\title{
Identification of Proteins and Phosphoproteins Using Pulsed Q Collision Induced Dissociation (PQD)
}

\author{
Wells W. Wu, ${ }^{1}$ Guanghui Wang, ${ }^{2}$ Paul A. Insel, ${ }^{3}$ Cheng-Te Hsiao, ${ }^{4}$ Sige Zou, ${ }^{4}$ \\ Stuart Maudsley, ${ }^{5}$ Bronwen Martin, ${ }^{1}$ Rong-Fong Shen ${ }^{1,6}$ \\ ${ }^{1}$ Laboratory of Clinical Investigation, National Institute on Aging, National Institutes of Health, Baltimore, MD 21224, USA \\ ${ }^{2}$ Proteomics Core Facility, National Heart, Lung, and Blood Institute, National Institutes of Health, Bethesda, MD 20892, USA \\ ${ }^{3}$ Department of Pharmacology and Medicine, University of California, San Diego, La Jolla CA 92093, USA \\ ${ }^{4}$ Laboratory of Experimental Gerontology, National Institute on Aging, National Institutes of Health, Baltimore, MD 21224, USA \\ ${ }^{5}$ Receptor Pharmacology Unit, National Institute on Aging, National Institutes of Health, Baltimore, MD 21224, USA \\ ${ }^{6}$ Center for Biologics Evaluation and Research, Food and Drug Administration, Bethesda, MD 20892, USA
}

\begin{abstract}
Pulsed Q collision induced dissociation (PQD) was developed to facilitate detection of low-mass reporter ions from labeling reagents (e.g., iTRAQ) in peptide quantification using an LTQ mass spectrometer (MS). Despite the large number of linear ion traps worldwide, the use and optimization of $P Q D$ for protein identification have been limited, in part due to less effective ion fragmentation relative to the collision induced dissociation (CID). PQD expands the $\mathrm{m} / \mathrm{z}$ coverage of fragment ions to the lower $\mathrm{m} / \mathrm{z}$ range by circumventing the typical low mass cut-off of an ion trap MS. Since database searching relies on the matching between theoretical and observed spectra, it is not clear how ion intensity and peak number might affect the outcomes of a database search. In this report, we systematically evaluated the attributes of PQD mass spectra, performed intensity optimization, and assessed the benefits of using PQD on the identification of peptides and phosphopeptides from an LTQ. Based on head-to-head comparisons between CID (higher intensity) and PQD (better $\mathrm{m} / \mathrm{z}$ coverage), peptides identified using PQD generally have Xcorr scores lower than those using CID. Such score differences were considerably diminished by the use of $0.1 \% \mathrm{~m}$-nitrobenzyl alcohol (m-NBA) in mobile phases. The ion intensities of both CID and PQD were adversely affected by increasing $\mathrm{m} / \mathrm{z}$ of the precursor, with PQD more sensitive than CID. In addition to negating the $1 / 3$ rule, $P Q D$ enhances direct bond cleavage and generates patterns of fragment ions different from those of CID, particularly for peptides with a labile functional group (e.g., phosphopeptides). The higher energy fragmentation pathway of PQD on peptide fragmentation was further compared to those of CID and the quadrupole-type activation in parallel experiments.
\end{abstract}

Key words: Pulsed $Q$ collision induced dissociation (PQD), Linear ion trap, Triple quadrupole $(Q q Q)$, Protein identification

Electronic supplementary material The online version of this article (doi:10.1007/s13361-011-0197-6) contains supplementary material, which is available to authorized users.

Correspondence to: Rong-Fong Shen; e-mail: rongfong.shen@fda.hhs.gov

\section{Introduction}

T inear ion trap (LIT) is one of the most extensively Lutilized mass spectrometers in proteomic research [1,2]. LIT employs resonance excitation during the collision- 
induced dissociation (CID) and is subject to the low mass cut off (LMCO) effect. LMCO exists because only ions above a certain $\mathrm{m} / \mathrm{z}$ are trapped with stable trajectories at a particular $q_{\text {eject }}$ value in a quadrupole ion trap [1]. Such an LMCO effect, dubbed the " $1 / 3$ rule", prevents ion trap mass spectrometers from detecting immonium ions or sequencing ions less than $\sim 1 / 3 \mathrm{~m} / z$ of precursor peptides.

Pulsed Q collision induced dissociation (PQD) was developed aiming to eliminate the LMCO effect using LTQ. PQD is regarded as a three-step process: (1) a short $(100 \mu$ s versus $30 \mathrm{~ms}$ in CID) precursor ion activation under a higher $\mathrm{Q}(0.7)$ and higher amplitude ( $8 \times$ that of CID); (2) the conversion of kinetic energy to internal energy at the high $Q$ for a short period of time (a delay time of $\sim 100 \mu \mathrm{s}$ ); and (3) the dissociation after Q pulsed down to trap fragment ions as low as $50 \mathrm{~m} / z$ [2]. In contrast, CID is a two-step process: both precursor ion activation and dissociation occur at a constant activation Q of 0.25 [2]. In either PQD or CID, the fragmentation occurs over a similar time scale and activation is achieved using supplementary voltage at a frequency equal to the distinct secular frequency of the precursor ion. From resonance excitation, the activated precursor ion gradually gains kinetic energy, which is converted to internal energy via collisions with the bath gas, leading to subsequent fragmentation [3].

Despite the large number of linear ion traps worldwide, reports on the use of PQD or its optimization for protein identification have been limited. This might in part be ascribed to the less effective fragmentation of PQD, compared with the CID [4, 5], as well as the greater interest of researchers in using PQD for proteomic quantification [410]. Although PQD spectra generally have a lower overall intensity, they expand the $\mathrm{m} / \mathrm{z}$ coverage of fragment ions to the lower $m / z$ range. While many database search algorithms rely on the matching of ion peaks and masses between observed and theoretical peptide spectra, they do not capitalize on the information of ion intensities. Given that PQD enhances direct bond cleavage [2], the intensities of fragment ions from PQD could be different from those of CID, particularly for those peptides with a labile functional group such as phosphopeptides (p-peptides). Thus, it would be of interest to see if PQD might yield information complementary to CID for peptide identification.

In this study, we focused on the identification of proteins by systematically exploring attributes of PQD mass spectra, parameters affecting peak intensity, and the potential benefit of performing PQD to identify peptides and p-peptides. We also compared the fragmentation pathway of PQD to that obtained from CID or quadrupole-type activation.

\section{Materials and Methods}

\section{Proteins, Peptides, and Cell Lysates}

Bovine serum albumin, $\beta$-galactosidase, $\alpha$-lactalbumin, $\beta$-lactoglobulin, lysozyme, apotransferrin, myoglobin, glu1-fibrinopeptide B (Glu-Fib), angiotensin I, and m-nitro- benzyl alcohol (m-NBA) were obtained from Sigma (St. Louis, MO, USA). P-peptides were purchased from Waters (Milford, MA, USA), Sigma, Invitrogen (Carlsbad, CA, USA), and custom synthesized. Peptide standards and B-galactosidase tryptic digest were obtained from Applied Biosystems (Framingham, MA, USA). Murine S49 wild type (WT) lymphoma cell lines were cultured in Dulbecco's modified Eagle's medium supplemented with $10 \%$ heat-inactivated horse serum and $10 \mathrm{mM}$ Hepes ( $\mathrm{pH}$ 7.4) in a humidified incubator at $37^{\circ} \mathrm{C}$ and $5 \% \mathrm{CO}_{2}$. For protein extraction, cells were cultured to a density of $\sim 3 \times 10^{6}$ cells $/ \mathrm{mL}$, harvested by centrifugation at $1200 \mathrm{rpm}(306 \times g)$, and pellets were washed six times with PBS. The cells were sonicated five times $(10 \mathrm{~s}$ each) with $1 \times$ protease and phosphatase inhibitor cocktail solution (Pierce, Rockford, IL, USA) and centrifuged at $100,000 \times g$ for $60 \mathrm{~min}$. The supernatant was saved as the cell lysate.

\section{Phosphoproteins (p-Proteins) Preparation}

P-proteins of WT S49 cells were extracted using a commercial IMAC (immobilized metal affinity chromatography) enrichment kit (Clontech, Mountain View, CA, USA). The eluted p-proteins were desalted using PD10 columns (GE Healthcare, UK) in $50 \mathrm{mM}$ ammonium bicarbonate prior to tryptic digestion.

\section{Liquid Chromatography and Ion Trap Mass Spectrometry}

Reduction, alkylation, and tryptic digestion of proteins were performed as described previously [11]. All samples (synthetic peptides, $0.2 \mu \mathrm{g}$ six-protein mixture, and $0.4 \mu \mathrm{g}$ IMAC enriched S49 WT p-proteins) were analyzed using a Thermo Fisher Scientific linear ion trap (LTQ/Orbitrap XL) by infusion or C18 reversed phase chromatography. For the latter, the elution was achieved with a linear gradient ( $2 \%-60 \%$ mobile phase B) for 25 or $55 \mathrm{~min}$, or otherwise specified [11]. In selected experiments, $0.1 \% \mathrm{~m}$-NBA was added in both mobile phases A (water with $0.1 \%$ formic acid) and B (acetonitrile with $0.1 \%$ formic acid). The data-dependent acquisition mode was enabled, and each survey MS scan was followed by four MS/MS scans (alternating CID/PQD on a common precursor ion), with the dynamic exclusion option. $\mathrm{CID} / \mathrm{PQD}_{\text {default }}$ denotes an alternate scheme with CID and default PQD parameter settings (activation $\mathrm{Q}$ of 0.7 ; activation time of $0.1 \mathrm{~ms}$ ); while $\mathrm{CID} / \mathrm{PQD}_{\text {modified }}$ denotes an alternate scheme with CID and modified PQD parameter settings (activation Q of 0.55 ; activation time of $0.4 \mathrm{~ms}$ ) [5]. The spray voltage and ion transfer tube temperature were set at $1.8 \mathrm{kV}$ and $160^{\circ} \mathrm{C}$, respectively.

\section{Database Search}

SEQUEST/Bioworks 3.3.1 SP1 was used to match MS/MS spectra to peptides in the SwissProt human or mouse databases. Spectra/peptide matches were considered significant if the following criteria were met: a normalized 
difference in cross-correlation score $(\Delta \mathrm{Cn})$ of at least 0.08 ; minimum cross-correlation score (XCorr) of 1.5 for $+1,2.0$ for +2 , and 2.5 for +3 charged ions; max XCorr rank 1 , and $\max \mathrm{Sp} \operatorname{rank} \leq 10$.

\section{Software Program to Perform In Silico Protein Digestion and Fragmentation}

A specific software program (FragIonStat.cpp) was written in $\mathrm{C}++$ to perform in silico enzyme digestion and ion fragmentation. Several rules were followed to generate the in silico tryptic peptides: (1) enzymatic digestion at K or R; (2) no miscleavage; (3) charge state of either two (no internal histidine) or three (with one internal histidine); and (4) precursor ion in the range of $400-1500 \mathrm{~m} / \mathrm{z}$. Peptides with $\geq 2$ internal histidines were disregarded, as they add complexity to our modeling. Moreover, the formation of fragment ions diminishes due to the sequestration of the mobile proton by the multiple histidines.

\section{Triple Quadrupole Mass Spectrometry}

Selected experiments were conducted on a QTrap 4000 MS equipped with a Tempo nano MDLC system and a nanospray ion source (Applied Biosystems). Spray voltage, interface heater temperature, curtain gas, ion source gas 1 , and declustering potential were set at $2.4 \mathrm{kV}, 140{ }^{\circ} \mathrm{C}, 10,20$, and 70, respectively. Q1 and Q3 were set at unit resolution $(0.7 \mathrm{Da})$ with scan rate of $4,000 \mathrm{~m} / \mathrm{z}$ per s. The collision energy was determined based on the mass and charge state of the given precursor ion, following the manufacturer's rolling collision energy algorithm. Data analysis was performed using the Analyst software (ver. 1.5).

\section{Results and Discussion}

\section{Factors Affecting PQD Fragmentation Efficiency}

As reported earlier by others [4,5], PQD is not as effective as CID in precursor fragmentation, although the underlying cause has not been adequately defined. We speculated that it might be the consequence of competition between resonance excitation and resonance ejection [3]. In CID, a relatively low voltage $(\leq 1-2 \mathrm{~V})$ is used in resonance excitation for ions to gain kinetic energy but remain inside the trap; while higher energy $(3-30 \mathrm{~V})$ is employed in resonance ejection to exceed the ion trapping field and elicit ion ejection [12]. The higher excitation amplitude used in PQD may cause a fraction of the precursor ions to be ejected before complete fragmentation takes place, resulting in reduced intensities of the product ions. It is also likely that a fraction of the activated precursor ions undergo dissociation during the $100 \mu$ s delay, thus reducing the detectable product ions. An approach, termed High Amplitude $\underline{\text { Short }}$ Time Excitation (HASTE), which pulses down Q after activation to observe ions below the LMCO, performs activation at a conventional
Q value of 0.25 [13]. Compared with HASTE, the trappingwell depths for precursor ions under PQD are deeper (due to higher Q applied), which presumably reduces the chance of undesirable resonance ejection of precursor ions.

To assess collision energy (CE) dependency, the peptide Glu-Fib was fragmented by varying the CE under CID or PQD. Supplemental Figure 1a shows that the optimized $\mathrm{CE}_{\mathrm{CID}}$ spreads over a broad peak and plateaus at $15 \%-40 \%$ $\mathrm{CE}$, while the optimized $\mathrm{CE}_{\mathrm{PQD}}$ has a sharper peak that centers around 30\% CE (Suppl. Figure 1b). These observations are consistent with those previously reported $[6,8]$. However, more careful analysis revealed that these seemingly different $\mathrm{CE}$ optimization plots are actually very similar if one takes into consideration the scales of energy inputs used during the optimization. The resonance excitation amplitude used for a selected CE under PQD is $\sim 8 \times$ that of CID. If the percent collision energy (normalized CE) on the $\mathrm{x}$ axis is replaced with the actual resonance excitation voltage, the peak widths of CID and PQD would be quite comparable. The practical implication is that $\mathrm{CE}_{\mathrm{PQD}}$ has to be more delicately tuned, due to the greater stride in energy per percentage change, to derive the optimal $\mathrm{CE}$ range for fragmentation.

The effect of CE on ion intensity using PQD was further illustrated with iTRAQ-labeled Glu-Fib. The TIC profile at various $\mathrm{CE}_{\mathrm{PQD}}(25 \%-35 \%)$ is shown at the top panel of Figure 1a. At $\mathrm{CE}$ of $28 \%$, the prominent ion is the unfragmented precursor $(\mathrm{m} / \mathrm{z}$ 858.4). Around CE $~ 30 \%$, both the precursor and fragment ions are clearly noticeable. This is different from the typical CID spectrum in which the precursor ion is often less prominent, if not totally negligible, at this CE level. Above CE 30\%, the precursor ion significantly diminishes (CE 32\%, Figure 1a). The effects of CE on TIC and intensities of the precursor, product, and reporter ions are shown in Figure 1b; both TIC and precursor ion intensity decrease rapidly between 25 and $28 \%$ CE. The precursor ion accounts for the bulk of the TIC (see Figure 1a, lower left). Of note, at CEs between $29 \%$ and $32 \%$, there is a continued decline of the precursor ion intensity but the TIC only decreases slightly. CE at $31 \%$ appears to be optimal for both the monitored product $(\mathrm{m} / \mathrm{z}$ 684.4) and the iTRAQ ions.

Table 1 lists the optimized CE ranges and associated total ion currents (TIC of MS2) for a variety of peptides. The optimal $\mathrm{CE}_{\mathrm{PQD}}$ for peptides with +1 to +4 charges ranges from $27 \%$ to $31 \%$ (Table 1a) on our LTQ. We noted that decreasing optimal $\mathrm{CE}_{\mathrm{PQD}}$ tends to occur with increasing charge state of the same peptide, e.g., ACTH (clip 1-17, +3 to +5 ) and peptide DVSLLHKPTTQISDFHVATR of $\beta$ galactosidase $(+4$ to +5$)$. This charge-state dependency is also noted in the $\mathrm{CE}_{\mathrm{CID}}$ for those peptides, although the ranges of "optimal" CID are much broader. This finding reiterates the importance of fine-tuning $\mathrm{CE}_{\mathrm{PQD}}$ in order to achieve optimal fragmentation of a target peptide. When CID is performed in a data-dependent manner, LTQ uses default $\% \mathrm{CE}$ that have been normalized (often at 35\%) 
(a)

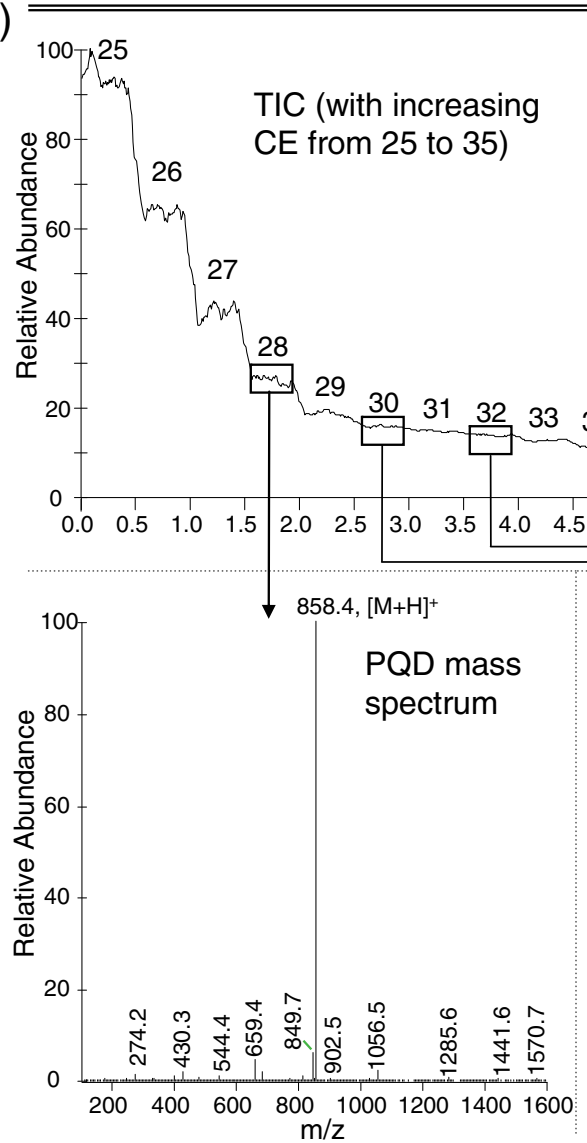

(b)

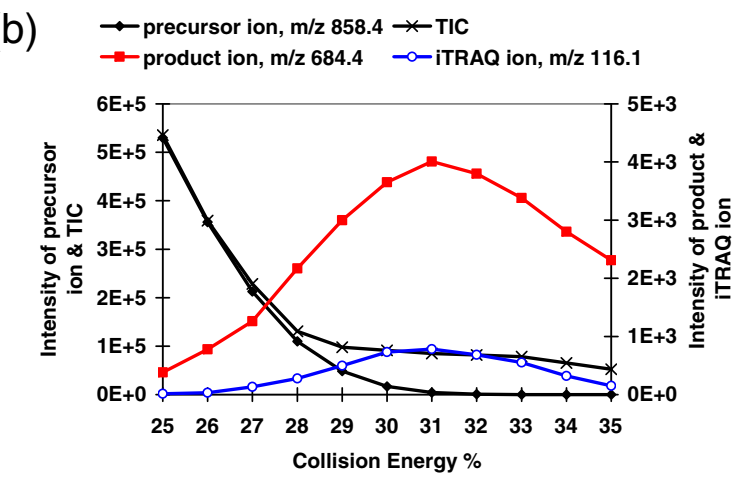

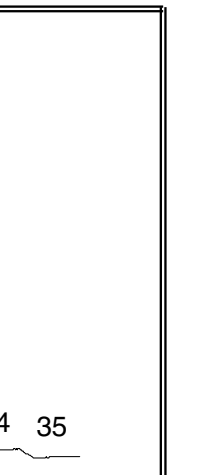

5.0 minute
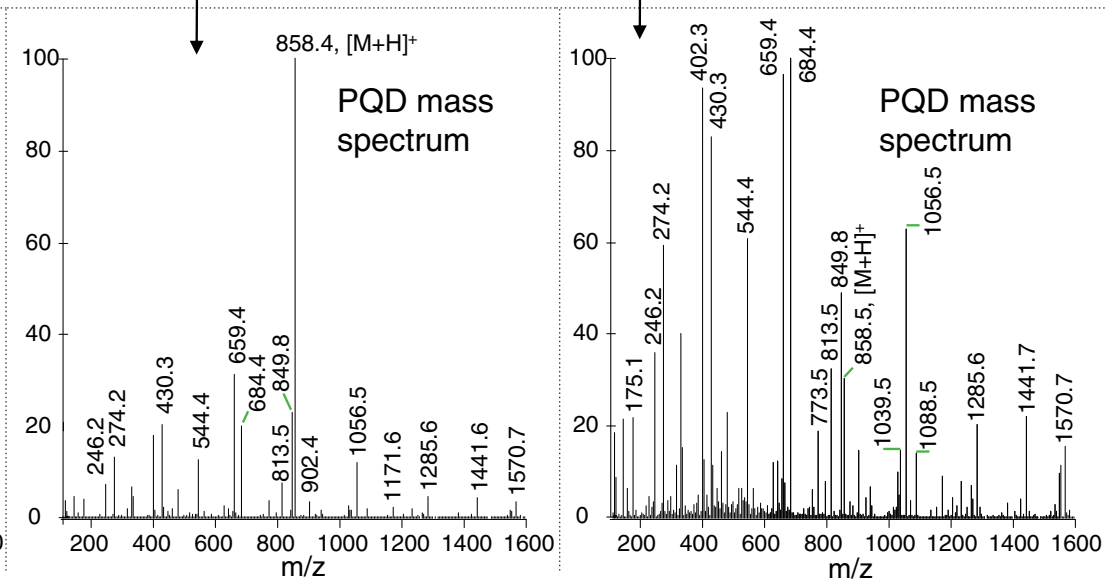

Figure 1. (a) Total ion current (TIC) profile with increasing collision energy (CE $\left.E_{P Q D}\right)$ on iTRAQ-labeled Glu-Fib B (0.5 pmol/ $\left./ \mathrm{l}\right)$. Samples were infused at $0.5 \mathrm{pmol} / \mu \mathrm{L}$ and the energy level was varied every $0.5 \mathrm{~min}$. (b) Effect of increasing $C E_{\mathrm{PQD}}$ on TIC, a precursor ion, a selected ion, and an iTRAQ ion

according to the $m / z$ of the precursors [14] and users seldom have to make adjustments. The observation thus suggests that there might be room for improving fragmentation, particular for peptides that exist in higher charge state $>4$.

A slight decrease in $\mathrm{CE}_{\mathrm{PQD}}(25 \%-27 \%)$ was observed for peptides susceptible to neutral losses (e.g., p-peptides) or to facile backbone cleavage at N-terminal to P (Table 1b). Both HTVLYISPPPEDLLDNSR and NVPLY(phos)K contain no potential neutral loss modification at the transitions studied but have relatively low $\mathrm{CE}_{\mathrm{PQD}}$. The two peptides likely can be preferentially fragmented at the $\mathrm{N}$-terminal to $\mathrm{P}$ due to multiple $\mathrm{P}$ and an enhanced V-P cleavage [15], respectively. On average, the $\mathrm{TIC}_{\mathrm{PQD}}$ was $49 \%$ of $\mathrm{TIC}_{\mathrm{CID}}$ for ions resulted from peptide bond cleavage (the typical $\mathrm{b}$ or $\mathrm{y}$ ions); and $78 \%$ of $\mathrm{TIC}_{\mathrm{CID}}$ for those due to neutral loss (e.g., loss of phosphoric acid) or bond cleavage at $\mathrm{N}$ terminal to $\mathrm{P}$ (Table 1b), respectively.

When TIC was plotted against precursor $\mathrm{m} / \mathrm{z}$ (from Table 1), both CID and PQD show a trend of decreasing fragmentation efficacy as the precursor $\mathrm{m} / \mathrm{z}$ becomes larger (Figure 2), consistent with a previous report showing that collisional activation mechanism is less effective in dissociating high mass ions [3]. The $\mathrm{m} / \mathrm{z}$ effect is more obvious with $\mathrm{PQD}$, as reflected by $<100 \% \mathrm{TIC}_{\mathrm{PQD}} / \mathrm{TIC}_{\mathrm{CID}}$ ratios
(Figure 2, red circles). However, there are instances in which $\mathrm{TIC}_{\mathrm{PQD}}$ is greater than (e.g., peptide ALELFR) or nearly equal to (e.g., peptide VNQIGT(phos)LSESIK) TIC CID $_{\text {. For }}$ ALELFR, the higher $\mathrm{TIC}_{\mathrm{PQD}}$ could be attributed to several low mass fragments ( $1, b 2$, and immonium ions) that otherwise would not register in $\mathrm{TIC}_{\mathrm{CID}}$ due to $\mathrm{LMCO}$ of $\mathrm{m} / \mathrm{z}$ 205 (data not shown).

It had been noted that the fragment ion intensities using PQD were 2- to 4-fold lower than those using CID [4, 5, 8]. In our hands, reduction in fragmentation efficiency could be as high as $90 \%$, i.e., $\mathrm{TIC}_{\mathrm{CID}} / \mathrm{TIC}_{\mathrm{PQD}}=\sim 10$ ). The decrease in fragmentation efficiency with increasing precursor $m / z$ (Figure 2) suggests that trypsin is preferred over Arg-C or Lys-C for PQD, as it generates shorter peptides (smaller $\mathrm{m} / \mathrm{z}$ ). In addition, the upper mass limit in PQD methods could be set at 1500 or less to confine the duty cycle within a mass range likely to yield higher fragment ions.

\section{Application of $P Q D$ to Peptide Identification}

The use of PQD enables detection of low $\mathrm{m} / \mathrm{z}$ ions in the spectra, which are typically excluded from CID spectra due to LMCO. To assess the extent of better ion coverage by PQD (relative to CID), a $\mathrm{C}++$ program (FragIonStat.cpp, see 
Table 1. The optimized CE ranges for listed transitions and total ion currents (TIC) of full-scan $\mathrm{MS}^{2}$ ions of synthetic and tryptic peptides. The peptides were infused at a concentration of $0.5-1 \mathrm{pmol} / \mu \mathrm{L}$ and a flow rate of $0.5 \mu \mathrm{L} / \mathrm{min}$

(a) Transitions involving sequence ions

\begin{tabular}{|c|c|c|c|c|}
\hline \multirow[t]{2}{*}{ Peptides } & \multicolumn{4}{|c|}{ Optimal CE and associated TIC } \\
\hline & CID & $\mathrm{TIC}^{\mathrm{a}}$ & $\mathrm{PQD}^{\mathrm{b}}$ & TIC \\
\hline $\begin{array}{l}\text { MRFA } \\
524.4(+1) \rightarrow 288.2(+1, \text { b2) }\end{array}$ & $15 \%-45 \%$ & $2.6 \mathrm{E} 5$ & $30 \%$ & $1.7 \mathrm{E} 5$ \\
\hline $\begin{array}{l}\text { Des-Arg1-bradykinin, PPGFSPFR } \\
452.7(+2) \rightarrow 404.4(+2, \text { y7) }\end{array}$ & $15 \%-60 \%$ & $5.5 \mathrm{E} 5$ & $31 \%$ & $5.3 \mathrm{E} 5$ \\
\hline $\begin{array}{l}\text { Angiotensin I, DRVYIHPFHL } \\
432.9(+3) \rightarrow 583.6(+2, \text { b } 9)\end{array}$ & $15 \%-40 \%$ & $5.7 \mathrm{E} 5$ & $29 \%$ & $5.6 \mathrm{E} 5$ \\
\hline $\begin{array}{l}\text { Glu1-fibrinopeptide B, EGVNDNEEGFFSAR } \\
785.8(+2) \rightarrow 684.4(+1, y 6)\end{array}$ & $15 \%-40 \%$ & $1.8 \mathrm{E} 5$ & $30 \%$ & $6.5 \mathrm{E} 4$ \\
\hline $\begin{array}{l}\text { ACTH (clip 1-17), SYSMEHFRWGKPVGKKR } \\
698.4(+3) \rightarrow 922.4(+2, \text { y } 15)\end{array}$ & $12 \%-50 \%$ & $5.2 \mathrm{E} 4$ & $31 \%$ & $2.3 \mathrm{E} 4$ \\
\hline $\begin{array}{l}\text { ACTH (clip 1-17), SYSMEHFRWGKPVGKKR } \\
524.0(+4) \rightarrow 615.3(+3, \text { y15) }\end{array}$ & $12 \%-40 \%$ & $4.3 \mathrm{E} 5$ & $28 \%$ & $3.5 \mathrm{E} 5$ \\
\hline $\begin{array}{l}\text { ACTH (clip } 1-17) \text {, SYSMEHFRWGKPVGKKR } \\
419.4(+5) \rightarrow 461.9(+4, y 15)\end{array}$ & $12 \%-40 \%$ & $3.5 \mathrm{E} 5$ & $26 \%$ & $3.0 \mathrm{E} 5$ \\
\hline $\begin{array}{l}\text { ACTH (clip 18-39), RPVKVYPNGAEDESAEAFPLEF } \\
822.4(+3) \rightarrow 1086.3(+2, \text { b20) }\end{array}$ & $15-40 \%$ & $2.1 \mathrm{E} 5$ & $27 \%$ & $6.9 \mathrm{E} 4$ \\
\hline $\begin{array}{l}\text { ACTH (clip 7-38), FRWGKPVGKKRRPVKVYPNGAEDESAEAFPLE } \\
732.4(+5) \rightarrow 789.6(+4, \text { b28) }\end{array}$ & $15 \%-45 \%$ & $3.7 \mathrm{E} 5$ & $27 \%$ & $1.7 \mathrm{E} 5$ \\
\hline $\begin{array}{l}\text { (myoglobin tryptic digest) YLEFISDAIIHVLHSK } \\
943.4(+2) \rightarrow 720.5(+1, \mathrm{y} 6)\end{array}$ & $15 \%-40 \%$ & $7.2 \mathrm{E} 5$ & $28 \%$ & $1.3 \mathrm{E} 5$ \\
\hline $\begin{array}{l}\text { (myoglobin tryptic digest) ALELFR } \\
748.6(+1) \rightarrow 435.3(+1, y 3)\end{array}$ & $15 \%-35 \%$ & $2.5 \mathrm{E} 5$ & $30 \%$ & $3.0 \mathrm{E} 5$ \\
\hline $\begin{array}{l}\text { (myoglobin tryptic digest) HGTVVLTALGGILK } \\
1378.8(+1) \rightarrow 1119.7(+1, \mathrm{~b} 12)\end{array}$ & $20 \%-40 \%$ & $2.2 \mathrm{E} 5$ & $28 \%$ & $1.2 \mathrm{E} 4$ \\
\hline $\begin{array}{l}\text { (myoglobin tryptic digest) LFTGHPETLEK } \\
1271.7(+1) \rightarrow 716.5(+1, y 6)\end{array}$ & $20 \%-45 \%$ & $1.5 \mathrm{E} 5$ & $31 \%$ & $2.3 \mathrm{E} 4$ \\
\hline $\begin{array}{l}\text { (myoglobin tryptic digest) GLSDGEWQQVLNVWGK } \\
1815.9(+1) \rightarrow 1443.7(+1, \text { y12) }\end{array}$ & $20 \%-40 \%$ & $9.2 \mathrm{E} 3$ & $31 \%$ & $8.5 \mathrm{E} 2$ \\
\hline $\begin{array}{l}\text { (myoglobin tryptic digest) VEADIAGHGQEVLIR } \\
1606.9(+1) \rightarrow 1192.7(+1, \text { y11) }\end{array}$ & $21 \%-42 \%$ & $6.3 \mathrm{E} 4$ & $31 \%$ & 2.4E3 \\
\hline $\begin{array}{l}(\beta \text { gal tryptic digest) IDPNAWVER } \\
550.3(+2) \rightarrow 589.5(+1, \mathrm{y} 4)\end{array}$ & $15 \%-45 \%$ & $1.2 \mathrm{E} 6$ & $28 \%$ & 4.6E5 \\
\hline $\begin{array}{l}(\beta \text { gal tryptic digest) VDEDQPFPAVPK } \\
671.3(+2) \rightarrow 755.5(+1, y 7)\end{array}$ & $15 \%-40 \%$ & $7.0 \mathrm{E} 5$ & $27 \%$ & $3.9 \mathrm{E} 5$ \\
\hline $\begin{array}{l}\text { ( } \$ \text { gal tryptic digest) APLDNDIGVSEATR } \\
729.4(+2) \rightarrow 719.5(+1, \text { y7) }\end{array}$ & $15 \%-40 \%$ & $7.2 \mathrm{E} 5$ & $29 \%$ & 2.2E5 \\
\hline $\begin{array}{l}\text { ( } \text { gal tryptic digest) DVSLLHKPTTQISDFHVATR } \\
567.7(+4) \rightarrow 684.9(+3, \mathrm{y} 18)\end{array}$ & $20 \%-45 \%$ & $5.2 \mathrm{E} 6$ & $27 \%$ & 4.3E6 \\
\hline $\begin{array}{l}\text { ( } 3 \text { gal tryptic digest) DVSLLHKPTTQISDFHVATR } \\
454.5(+5) \rightarrow 513.8(+4, \mathrm{y} 18)\end{array}$ & $10 \%-45 \%$ & $3.1 \mathrm{E} 6$ & $25 \%$ & $2.9 \mathrm{E} 6$ \\
\hline $\begin{array}{l}\text { HTVLYISPPPEDLLDNSR } \\
690.2(+3) \rightarrow 717.4(+1, y 6)\end{array}$ & $15 \%-50 \%$ & $1.8 \mathrm{E} 6$ & $30 \%$ & $5.4 \mathrm{E} 5$ \\
\hline $\begin{array}{l}\text { HTVLYISPPPEDLLDNS(phos)R } \\
716.9(+3) \rightarrow 358.3\left(+1, \mathrm{y} 3-\mathrm{H}_{3} \mathrm{PO}_{4}\right)\end{array}$ & $15 \%-45 \%$ & $3.6 \mathrm{E} 5$ & $31 \%$ & $7.5 \mathrm{E} 4$ \\
\hline $\begin{array}{l}\text { FQS(phos)EEQQQTEDELQDK (ß casein) } \\
1031.7(+2) \rightarrow 747.4(+1, \text { y6) }\end{array}$ & $20 \%-40 \%$ & $9.1 \mathrm{E} 4$ & $30 \%$ & $8.7 \mathrm{E} 3$ \\
\hline $\begin{array}{l}\text { HLADLS(phos)K } \\
432.2(+2) \rightarrow 437.3(+1, \text { b4) }\end{array}$ & $15 \%-30 \%$ & $9.5 \mathrm{E} 5$ & $29 \%$ & 7.6E5 \\
\hline $\begin{array}{l}\text { VNQIGT(phos)LSESIK } \\
684.8(+2) \rightarrow 816.2\left(+1, \text { y8 }-\mathrm{H}_{3} \mathrm{PO}_{4}\right)\end{array}$ & $15 \%-50 \%$ & 7.7E5 & $30 \%$ & $2.8 \mathrm{E} 5$ \\
\hline $\begin{array}{l}\text { VNQIGTLS(phos)ES(phos)IK } \\
724.8(+2) \rightarrow 896.4\left(+1, \text { y8 }-\mathrm{H}_{3} \mathrm{PO}_{4}\right)\end{array}$ & $15 \%-45 \%$ & 9.9E4 & $29 \%$ & $3.5 \mathrm{E} 4$ \\
\hline $\begin{array}{l}\text { (b) Transitions involving preferential neutral loss or cleavages } \mathrm{N} \text { terminal } \\
\text { HTVLYISPPPEDLLDNSR } \\
690.2(+3) \rightarrow 627.2(+2, \mathrm{y} 11)\end{array}$ & $15 \%-50 \%$ & $1.8 \mathrm{E} 6$ & $25 \%$ & $1.3 \mathrm{E} 6$ \\
\hline $\begin{array}{l}\text { NVPLY(phos)K } \\
407.2(+2) \rightarrow 600.4(+1, y 4)\end{array}$ & $15 \%-50 \%$ & $2.7 \mathrm{E} 5$ & $26 \%$ & 2.4E5 \\
\hline $\begin{array}{l}\text { FQS(phos)EEQQQTEDELQDK ( }(\text { casein) } \\
1031.7(+2) \rightarrow 982.6(+2, \text { neutral loss of phos) }\end{array}$ & $20 \%-40 \%$ & $9.1 \mathrm{E} 4$ & $26 \%$ & $1.3 \mathrm{E} 4$ \\
\hline $\begin{array}{l}\text { HLADLS(phos)K } \\
432.2(+2) \rightarrow 383.3(+2, \text { neutral loss of phos })\end{array}$ & $15 \%-50 \%$ & $9.5 \mathrm{E} 5$ & $27 \%$ & $9.2 \mathrm{E} 5$ \\
\hline $\begin{array}{l}\text { VNQIGT(phos)LSESIK } \\
684.8(+2) \rightarrow 635.9(+2, \text { neutral loss of phos) }\end{array}$ & $15 \%-45 \%$ & 7.7E5 & $25 \%$ & 7.7E5 \\
\hline $\begin{array}{l}\text { VNQIGTLS(phos)ES(phos)IK } \\
724.8(+2) \rightarrow 676.0 \text { ( }+2, \text { neutral loss of phos) }\end{array}$ & $15 \%-40 \%$ & $9.9 \mathrm{E} 4$ & $25 \%$ & 9.4E4 \\
\hline
\end{tabular}

${ }^{\mathrm{a}} \mathrm{TIC}$ at $\mathrm{CE}$ of $35 \%$

${ }^{\mathrm{b}}$ Default settings (activation Q of 0.7 and activation time of $0.1 \mathrm{~ms}$ ) 


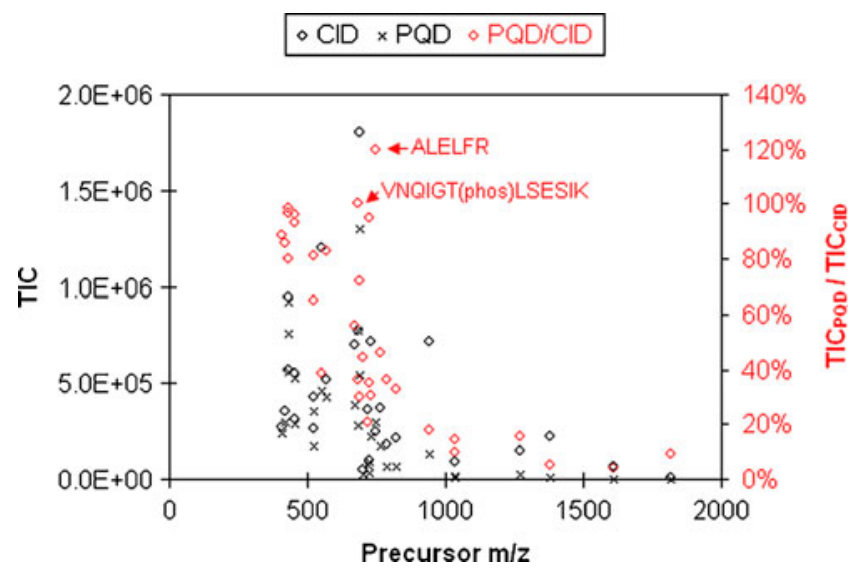

Figure 2. The levels of TIC of full-scan MSMS using CID (black diamond) or PQD (cross) at different precursor $\mathrm{m} / \mathrm{z}$ (left y axis); and relative ratios of $\mathrm{TIC}_{\mathrm{PQD}} / \mathrm{TIC}_{\mathrm{CID}}$ (red diamond), as indicated by the right $y$ axis

"Materials and Methods") was written and used to count detectable fragment ions from peptides generated by in silico digestion of human RefSeq protein sequences $(38,072$ entries). A total of 432,805 unique peptides were generated. The numbers of $b$ or $y$ ions detectable under PQD and CID are 14,156,991 and 12,944,609, respectively, suggesting that nearly $10 \%$ of $\mathrm{b}$ or $\mathrm{y}$ ions are lost upon CID due to LMCO.

We tested two alternate CID/PQD fragmentation methods, CID/PQD default $_{\text {and }}$ CID/PQD modified $_{\text {using a six-protein }}$ mixture. Supplemental Tables 1 and 2 list peptides identified and their associated database search results. For comparison, we also show Xcorr scores using CID or PQD alone. Table 2 summarizes the number of peptides identified for each protein. $\mathrm{PQD}_{\text {modified }}$ settings are reported to increase iTRAQ reporter ion intensities and to improve reliability in quantification [5], but effect on protein identification has not been described. From the greater number of peptide identified (Table 2), $\mathrm{PQD}_{\text {modified }}$ appears to improve protein identification. However, we found $>75 \%$ and $\sim 70 \%$ of peptides identified using $\mathrm{PQD}_{\text {default }}$ and $\mathrm{PQD}_{\text {modified, }}$, respectively, have XCorr scores less than the same peptides identified with CID (Suppl. Figure 2). Thus, despite the improved coverage of sequencing ions, no apparent improvement in peptide identification (i.e., XCorr) occurs by the use of PQD. The higher fragment ion intensity of CID probably outweighs the improved sequencing ion coverage of PQD.

Kjeldsen et al. reported that inclusion of $0.1 \% \mathrm{~m}$ nitrobenzyl alcohol (m-NBA) in the mobile phases significantly improves peptide sequencing by electron transfer dissociation (ETD) [16]. The benefit was ascribed to the shifting to higher charge states of tryptic peptides, without an appreciable effect on chromatography [16]. Since the fragmentation efficiency of PQD declines more rapidly than CID with increasing $m / z$ (Figure 2), we hypothesize that by promoting a peptide to higher charge states (e.g., $+2 \rightarrow+3$, thus deceasing $\mathrm{m} / \mathrm{z}$ ) under PQD fragmentation, one might achieve better protein identification. We thus added $0.1 \% \mathrm{~m}$ NBA in the mobile phase buffers (both $A$ and B) and analyzed the six-protien digest using the alternate CID/

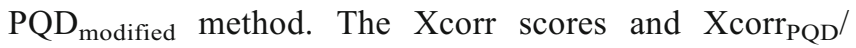
$\mathrm{Xcorr}_{\mathrm{CID}}$ ratios of peptides, obtained by database searching, are shown in Suppl. Table 3. The improvement in Xcorr scores by using m-NBA in the buffers is apparent from the scores presented by the box and whisker plot shown in Suppl. Figure 2 (from $\mathrm{PQD}_{\text {modified }}$ to $\mathrm{PQD}_{\text {modified }}$ using $\mathrm{m}$ NBA, the mean score improved from 0.90 to 0.98 and the $P$ value from a two-sample $t$-test was 1.02E-14). Such improvement in Xcorr scores, together with the benefit of overcoming the LMCO effect, should expand the utility of PQD in applications where detection of small ion fragments is desirable. For example, despite not being weighted in the algorithm of Sequest-based searching engines such as BioWorks [17], immonium ions or small N- or C-terminal fragments (e.g., y1, etc.) in a spectrum may assist in manual peptide identification, especially for those with borderline scores. In general, b1 ions are not stable enough to be observed during the fragmentation of underivatized peptides [18]. However, derivatization at the N-terminus with iTRAQ promotes the formation of b1 ions [19], which are readily observable under the PQD mode.

\section{Higher Energy Fragmentation Pathway of $P Q D$ and Application to p-Peptide Identification}

The spectra from $\mathrm{PQD}$ resemble those of a triple quadrupole mass spectrometer (QqQ). Figure 3 illustrates such resemblance by comparing the spectra of a peptide HTVLYISPPPEDLLDNSR (+3) using PQD or CID on an LTQ or beamtype fragmentation method on a QqQ (ABI Qtrap 4000). The prevalence of $\mathrm{y}$ ions cleaved at $\mathrm{N}$-terminal to $\mathrm{P}$ under CID could be explained from the "mobile proton" model of peptide fragmentation [20] and the "proline" effect (due to its high gas phase basicity [15]). In contrast, breaks that are more even at peptide bonds are seen with PQD, presumably due to more energetic collisions of the precursor ion with the bath gas via higher energy fragmentation pathways. Similar to the HASTE approach,

Table 2. The number of peptides identified with $P Q D_{\text {default }}$ or $P Q D_{\text {modified }}$ settings from the tryptic digest of a six-protein mixture

\begin{tabular}{lccccr}
\hline & ALBU & TRFE & BGAL & LACB & LALBA \\
\cline { 2 - 5 } No. of peptide ID in PQD & 142 & 104 & 38 & 126 & 38 \\
No. of peptide ID in PQD & 159 & 120 & 52 & 162 & 170 \\
\hline
\end{tabular}

$\mathrm{ALBU}=$ bovine serum albumin; TRFE $=$ apotransferrin; $\mathrm{BGAL}=\beta$-galactosidase; $\mathrm{LACB}=\beta$-lactoglobulin; $\mathrm{LALBA}=\alpha$-lactalbumin; $\mathrm{LYSC}=$ lysozyme 

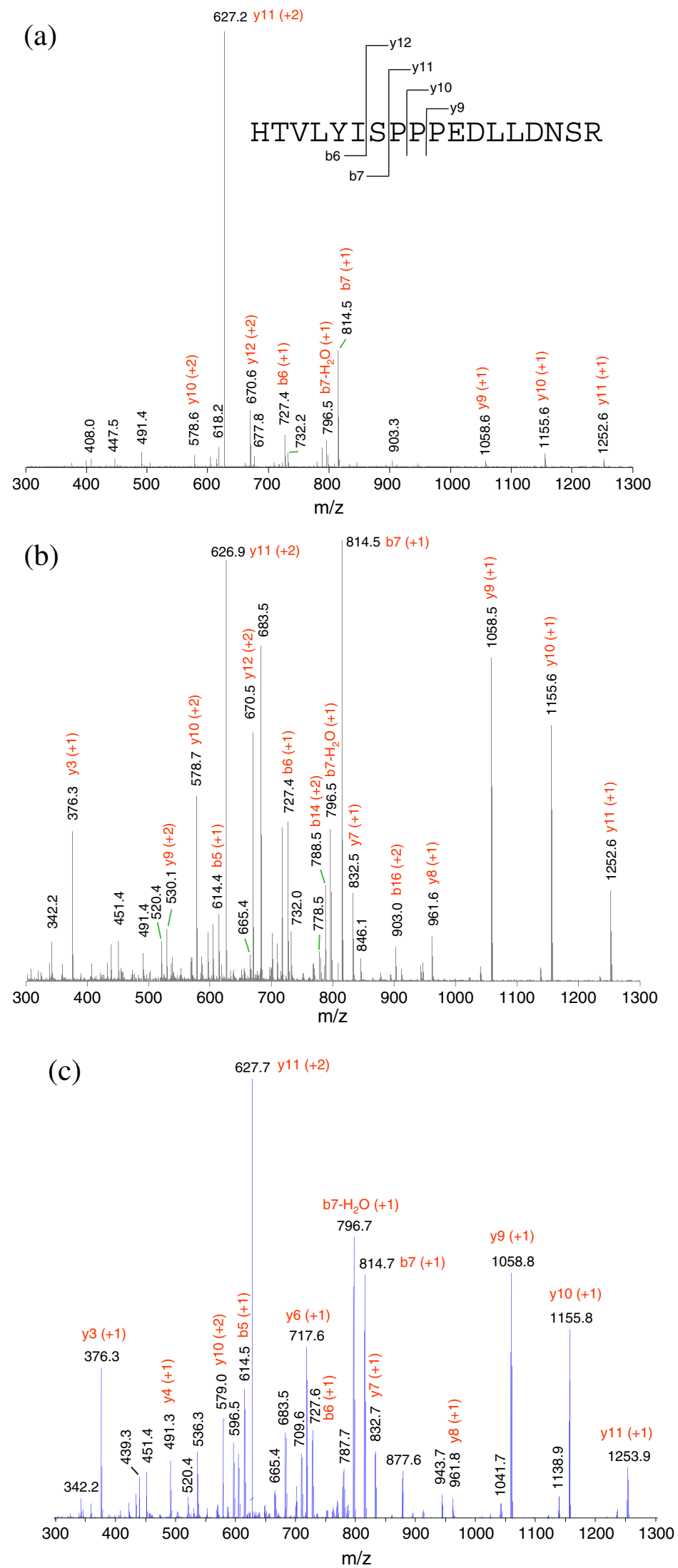

Figure 3. (a) CID and (b) PQD mass spectra of triply charged HTVLYISPPPEDLLDNSR (from ToneBP protein) acquired at collision energy of $35 \%$ on an LTQ. (c) Mass spectrum acquired with triple quadrupole-type collision at CE 33 on a QTrap 4000 MS 

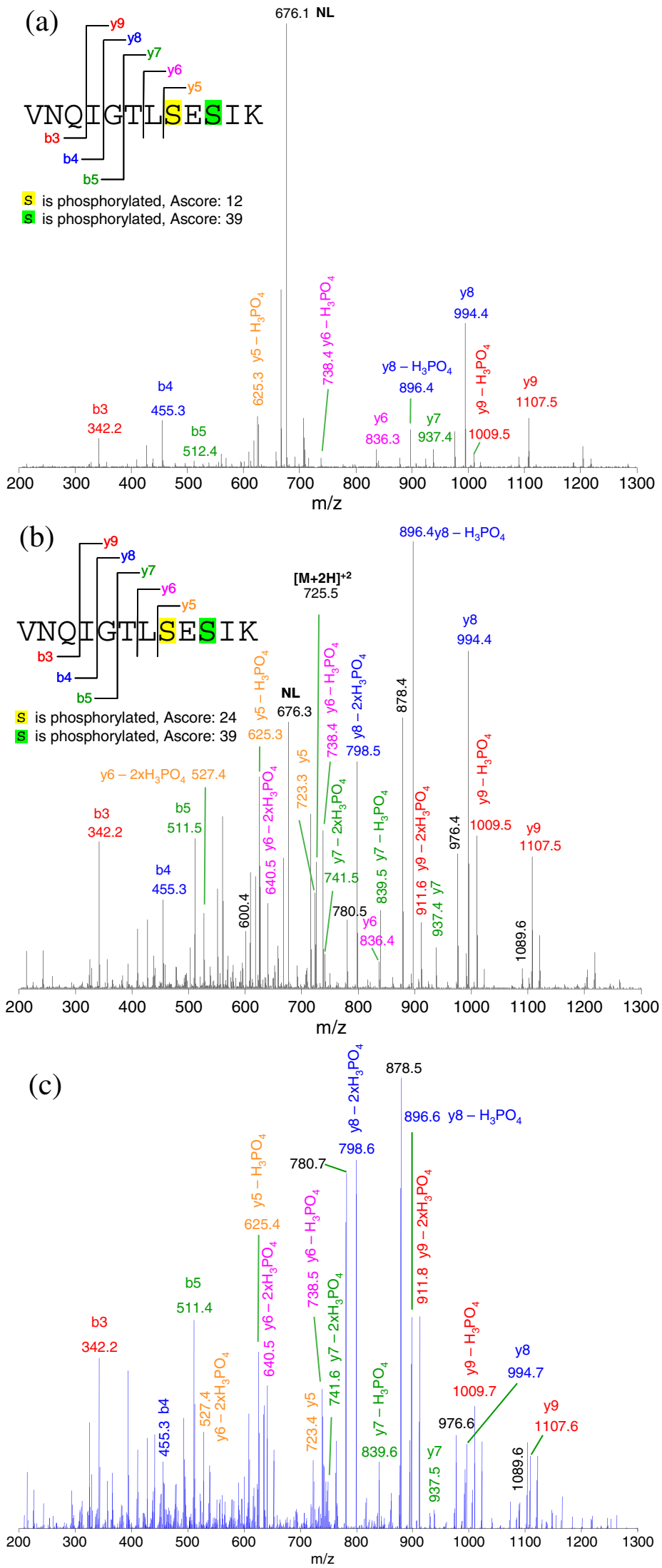

Figure 4. Tandem mass spectra of (a) conventional CID, (b) PQD, and (c) triple quadrupole-type collision, respectively, of VNQIGTLS(phos)ES(phos)IK. Some fragment ions are labeled. The collision energies were $35 \%, 28 \%$, and 41 for CID, PQD, and QqQ (based on rolling collision energy of Qtrap 4000), respectively 
more internal energy is deposited to the precursor ion under PQD [13]. The higher energy fragmentation pathway likely promotes delocalizing protons from sequestered sites to generate more even cleavage across the peptide backbone (Figure 3b). Thus, a PQD spectrum (Figure 3b) bears resemblance to that of QqQ (Figure 3c). The preferential fragmentation at the $\mathrm{N}$-terminal to $\mathrm{P}$ in CID has been well noted $[15,20]$, although difference in mass spectral features between CID and PQD is not always as marked as seen with the peptide HTVLYISPPPEDLLDNSR (e.g., see CID and PQD of angiotensin I, DRVYIHPFHL, in Suppl. Figure 3). However the prevalence of $\mathrm{y}$ ions cleaved at $\mathrm{N}$-terminal to $\mathrm{P}$ in CID, if observed, well resembles the neutral loss ions from p-peptides. A well-recognized drawback using ion-trap CID on Ser- or Thr-containing p-peptides is the formation of "neutral loss" ions due to inefficient peptide-bond cleavages. While CID works by resonance excitation of a precursor ion with defined supplementary voltage, the derived "neutral loss' ion [e.g., loss $98 \mathrm{Da}\left(-\mathrm{H}_{3} \mathrm{PO}_{4}\right)$ from a p-peptide] is no longer in resonance with the applied voltage. Hence, no additional kinetic energy is gained and the ion is cooled down by the bath gas [13]. In contrast, QqQ MS uses beam-type CID to cleave the backbone of a peptide en route to Q3 whether it is a precursor or a product, thus generating richer sequence information [21]. Figure $4 \mathrm{a}-\mathrm{c}$ demonstrate the tandem mass spectra of the peptide VNQIGTLS(phos)ES(phos)IK using CID, PQD, and QqQ-type collision. The facile neutral loss cleavage seen with CID (Figure 4a) is not as prominent with PQD (Figure 4b), while the PQD spectrum resembles that of QqQ-type collision (Figure 4c). Similar observation was noted with a mono-phosphorylated peptide FQS(phos) EEQQQTEDELQDK (Suppl. Figure 4).

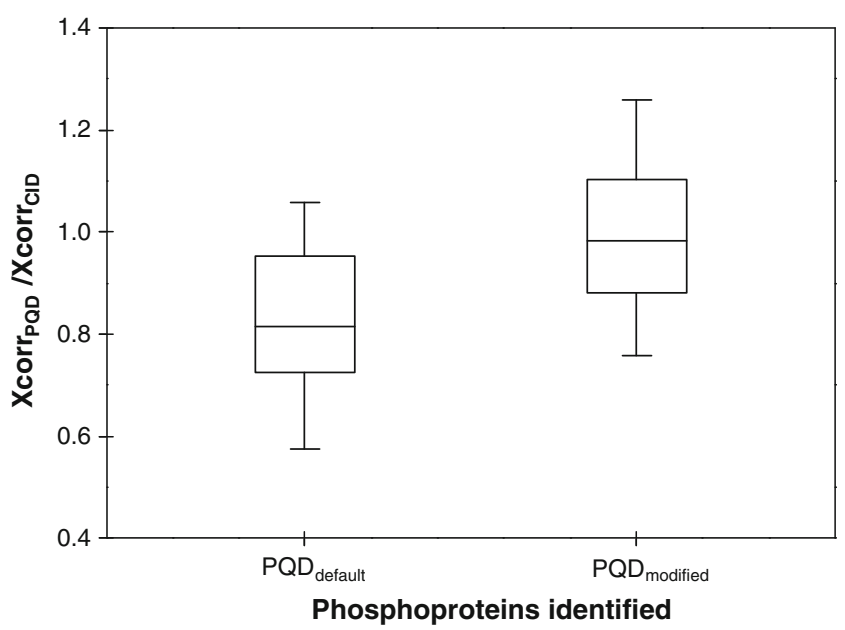

Figure 5. Box and whisker plot of relative Xcorr scores (Xcorr XQD $_{\mathrm{P}} /$ Xcorr $\left._{\mathrm{CID}}\right)$, using $\mathrm{PQD}_{\text {default }}$ and $\mathrm{PQD}_{\text {modified }}$ settings, for the phosphoproteins identified with at least two distinct p-peptides
To evaluate whether such direct bond cleavage can aid in p-peptide identification in a complex proteome, we analyze a tryptic digest of IMAC-enriched p-proteins from S49 cell lysates. We used the alternate CID and PQD method akin to that described above for the six-protein mixture. We identified 124 and 126 proteins using the $\mathrm{CID} / \mathrm{PQD}_{\text {default }}$ and $\mathrm{CID} / \mathrm{PQD}_{\text {modified }}$ settings, respectively (see Suppl. Tables 4 and 5). At least one p-peptide was identified for 66 proteins $(53 \%)$ detected from CID/PQD default and 75 proteins $(60 \%)$ with $\mathrm{CID} / \mathrm{PQD} \mathrm{D}_{\text {modified. }}$. Figure 5 shows the ratios of XCorr scores $\left(\mathrm{X}\right.$ corr $\left._{\mathrm{PQD}} / \mathrm{Xcorr}_{\mathrm{CID}}\right)$ for p-proteins using the alternate $\mathrm{CID} / \mathrm{PQD}_{\text {default }}$ or $\mathrm{CID} / \mathrm{PQD}$ modified (from Suppl. Tables 4 and 5). Most p-peptides identified with $\mathrm{PQD}_{\text {default }}$ have lower XCorr scores relative to the counterparts identified with CID but p-peptides identified with $\mathrm{PQD}_{\text {modified }}$ have XCorr scores comparable to those obtained using CID. Given that $\mathrm{PQD}_{\text {modified }}$ obviates the LMCO effect without compromising XCorr scores, it may potentially serve as an alternative method to CID for p-peptide analysis.

To assess the precision of assigning sites of phosphorylation, we used the Ascore program, which measures the probability of a correct phosphorylation site based on the presence and intensity of site-determining ions in an MS/MS spectrum [22]. The Ascore for the S8 phosphorylation on a short p-peptide VNQIGTLS(phos)ES(phos)IK ( $\mathrm{m} / \mathrm{z}: 724.8)$ from CID was considered "insignificant" (Ascore $<19$, Figure $4 a$ ), yet $99 \%$ confident (Ascore $>19$, Figure $4 b$ ) from PQD. Such improvement was lost for a longer p-peptide (e.g., FQS(phos)EEQQQTEDELQDK, precursor $\mathrm{m} / \mathrm{z}$ : 1031.7, Suppl. Figure $4 \mathrm{a}$ and $\mathrm{b}$ ), which is likely attributable to the reduced fragmentation efficiency of PQD for higher $\mathrm{m} / \mathrm{z}$ ions (Figure 2). We found that the MS2 ion intensity of FQS(phos) EEQQQTEDELQDK under PQD decreases nearly an order of magnitude from that of CID, while that of VNQIGTLS(phos)

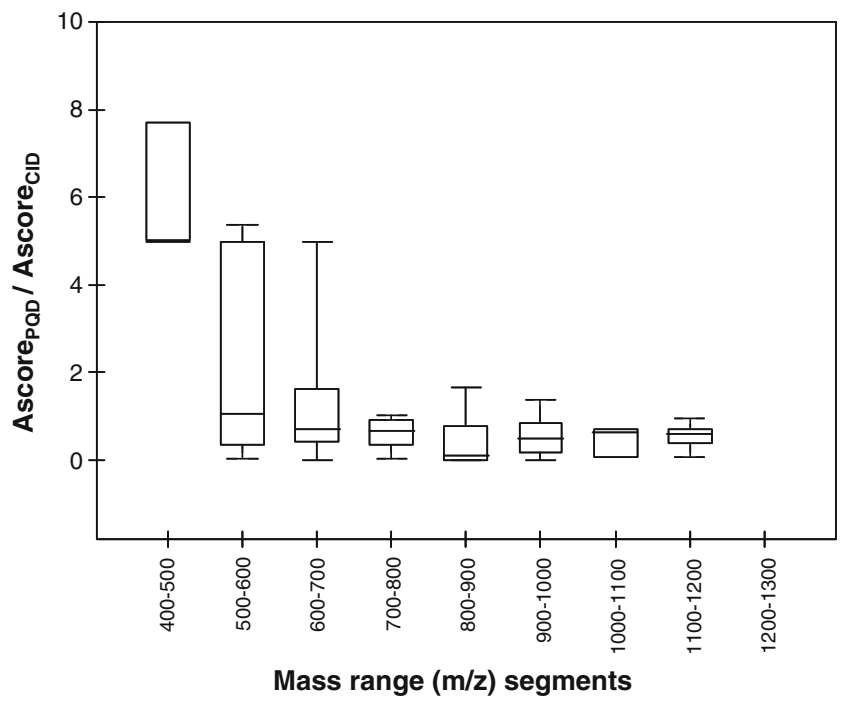

Figure 6. Box and whisker plot of the ratios of Ascores $\left(\mathrm{PQD}_{\text {modified }} / \mathrm{CID}\right)$ of phosphopeptides having increasing $\mathrm{m} / \mathrm{z}$. Phosphopeptides were identified from wild-type S49 cell lysate 
ES(phos)IK decreases only one-third (Table 1a). The nearly one-order decrease in MS2 ion intensity could adversely affect its Ascore, while a one-third drop in MS2 intensity might have been compensated by the richness of MS2 information needed for the Ascore calculation. Figure 6 shows that Ascores of ppeptides from the IMAC-enriched p-proteins of S49 cells largely decrease (expressed as Ascore $_{\mathrm{PQD}} /$ Ascore $_{\mathrm{CID}}$ ) with increasing $m / z$.

For phosphotyrosine containing p-peptides, the loss of phosphoric acid (-98 Da) upon CID is caused by gasphase phosphate group rearrangement during the relatively long (ms) activation time in an ion trap [23, 24]. Such a rearrangement is absent in a QqQ-type MS, which operates at $\mu$ s activation time scale [25]. We evaluated the effects of short $(0.1 \mathrm{~ms})$ PQD activation on $\mathrm{pY}$ containing peptides. Suppl. Figure $5 \mathrm{a}$ and $\mathrm{b}$ show the loss of $\mathrm{H}_{3} \mathrm{PO}_{4}$ and $\mathrm{HPO}_{3}$ upon CID (default $30 \mathrm{~ms}$ activation time) or PQD (0.1 ms) on TRDIY(phos)ETDYYRK. The patterns are similar, except that PQD yielded relatively lower intensities of the "neutral loss" peaks. By contrast, only a trace amount of "neutral loss" ions was observed on a QqQ MS instrument (Suppl. Figure 5c). These results suggest that rearrangement of the phosphate group could be inherent to the resonance activation process in an ion trap, regardless of the activation time scale. Such notion, however, requires further validation with more pY-containing peptides.

\section{Acknowledgments}

The authors acknowledge support for this work by the Intramural Research Programs of National Institute on Aging and National Heart, Lung, and Blood Institute, National Institutes of Health (NIH). They acknowledge the following for technical advice: Dr. Howard Jaffe, NINDS, NIH; Drs. Jae C. Schwartz, Mike W. Senko, and John E. P. Syka of ThermoFisher Scientific Inc.

\section{References}

1. Louris, J.N., Cooks, R.G., Syka, J.E.P., Kelley, P.E., Stafford, G.C., Todd, J.F.J.: Instrumentation, applications, and energy deposition in quadrupole ion-trap tandem mass-spectrometry. Anal. Chem. 59, 16771685 (1987)

2. Schwartz, J.C., Syka, J.E.P., Quarmby, S.T.: Improving the Fundamentals of MSn on 2D Linear Ion Traps: New Ion Activation and Isolation Techniques. The 53rd ASMS Conference on Mass Spectrometry and Allied Topic, San Antonio, TX, June 5-9 (2005)

3. McLuckey, S.A.: Principles of collisional activation in analytical massspectrometry. J. Am. Soc. Mass Spectrom. 3, 599-614 (1992)

4. Guo, T., Gan, C.S., Zhang, H., Zhu, Y., Kon, O.L., Sze, S.K.: Hybridization of pulsed-Q dissociation and collision-activated dissociation in linear ion trap mass spectrometer for iTRAQ quantitation. $J$. Proteome Res. 7, 4831-4840 (2008)

5. Bantscheff, M., Boesche, M., Eberhard, D., Matthieson, T., Sweetman, G., Kuster, B.: Robust and sensitive iTRAQ quantification on an LTQ orbitrap mass spectrometer. Mol. Cell Proteom. 7, 1702-1713 (2008)

6. Griffin, T.J., Xie, H., Bandhakavi, S., Popko, J., Mohan, A., Carlis, J.V., Higgins, L.: iTRAQ reagent-based quantitative proteomic analysis on a linear ion trap mass spectrometer. J. Proteome Res. 6, 4200-4209 (2007)
7. Armenta, J.M., Hoeschele, I., Lazar, I.M.: Differential protein expression analysis using stable isotope labeling and PQD linear ion trap MS technology. J. Am. Soc. Mass Spectrom. 20, 1287-1302 (2009)

8. Yang, F., Wu, S., Stenoien, D.L., Zhao, R., Monroe, M.E., Gritsenko, M.A., Purvine, S.O., Polpitiya, A.D., Tolic, N., Zhang, Q., Norbeck, A.D., Orton, D.J., Moore, R.J., Tang, K., Anderson, G. A., Pasa-Tolic, L., Camp, D.G., Smith, R.D.: Combined pulsed-Q dissociation and electron transfer dissociation for identification and quantification of iTRAQ-labeled phosphopeptides. Anal. Chem. 81, 4137-4143 (2009)

9. Kocher, T., Pichler, P., Schutzbier, M., Stingl, C., Kaul, A., Teucher, N., Hasenfuss, G., Penninger, J.M., Mechtler, K.: High precision quantitative proteomics using iTRAQ on an LTQ orbitrap: a new mass spectrometric method combining the benefits of all. J. Proteome Res. 8, 4743-4752 (2009)

10. Savitski, M.M., Fischer, F., Mathieson, T., Sweetman, G., Lang, M., Bantscheff, M.: Targeted data acquisition for improved reproducibility and robustness of proteomic mass spectrometry assays. J. Am. Soc. Mass Spectrom. 21, 1668-1679 (2010)

11. Wu, W.W., Wang, G., Yu, M.J., Knepper, M.A., Shen, R.F.: Identification and quantification of basic and acidic proteins using solution-based two-dimensional protein fractionation and label-free or 180-labeling mass spectrometry. J. Proteome Res. 6, 2447-2459 (2007)

12. Charles, M.J., McLuckey, S.A., Glish, G.L.: Competition between resonance ejection and ion dissociation during resonant excitation in A quadrupole ion-trap. J. Am. Soc. Mass Spectrom. 5, 1031-1041 (1994)

13. Cunningham Jr., C., Glish, G.L., Burinsky, D.J.: High amplitude short time excitation: a method to form and detect low mass product ions in a quadrupole ion trap mass spectrometer. J. Am. Soc. Mass Spectrom. 17, 81-84 (2006)

14. Lopez, L.L., Tiller, P.R., Senko, M.W., Schwartz, J.C.: Automated strategies for obtaining standardized collisionally induced dissociation spectra on a benchtop ion trap mass spectrometer. Rapid Commun. Mass Spectrom. 13, 663-668 (1999)

15. Breci, L.A., Tabb, D.L., Yates III, J.R., Wysocki, V.H.: Cleavage Nterminal to proline: analysis of a database of peptide tandem mass spectra. Anal. Chem. 75, 1963-1971 (2003)

16. Kjeldsen, F., Giessing, A.M., Ingrell, C.R., Jensen, O.N.: Peptide sequencing and characterization of post-translational modifications by enhanced ion-charging and liquid chromatography electron-transfer dissociation tandem mass spectrometry. Anal. Chem. 79, 9243-9252 (2007)

17. Hohmann, L.J., Eng, J.K., Gemmill, A., Klimek, J., Vitek, O., Reid, G.E., Martin, D.B.: Quantification of the compositional information provided by immonium ions on a quadrupole-time-of-flight mass spectrometer. Anal. Chem. 80, 5596-5606 (2008)

18. Summerfield, S.G., Bolgar, M.S., Gaskell, S.J.: Promotion and stabilization of $b(1)$ ions in peptide phenylthiocarbamoyl derivatives: analogies with condensed-phase chemistry. J. Mass Spectrom. 32, 225231 (1997)

19. Wiese, S., Reidegeld, K.A., Meyer, H.E., Warscheid, B.: Protein labeling by iTRAQ: a new tool for quantitative mass spectrometry in proteome research. Proteomics 7, 340-350 (2007)

20. Wysocki, V.H., Tsaprailis, G., Smith, L.L., Breci, L.A.: Mobile and localized protons: a framework for understanding peptide dissociation. J. Mass Spectrom. 35, 1399-1406 (2000)

21. Xia, Y., Liang, X., McLuckey, S.A.: Ion trap versus low-eenergy beamtype collision-induced dissociation of protonated ubiquitin ions. Anal. Chem. 78, 1218-1227 (2006)

22. Beausoleil, S.A., Villen, J., Gerber, S.A., Rush, J., Gygi, S.P.: A probability-based approach for high-throughput protein phosphorylation analysis and site localization. Nat. Biotechnol. 24, 1285-1292 (2006)

23. DeGnore, J.P., Qin, J.: Fragmentation of phosphopeptides in an ion trap mass spectrometer. J. Am. Soc. Mass Spectrom. 9, 1175-1188 (1998)

24. Moyer, S.C., Cotter, R.J., Woods, A.S.: Fragmentation of phosphopeptides by atmospheric pressure MALDI and ESI/Ion trap mass spectrometry. J. Am. Soc. Mass Spectrom. 13, 274-283 (2002)

25. Palumbo, A.M., Reid, G.E.: Evaluation of gas-phase rearrangement and competing fragmentation reactions on protein phosphorylation site assignment using collision induced dissociation-MS/MS and MS (3). Anal. Chem. 80, 9735-9747 (2008) 